\title{
Selective Conventional Transarterial Chemoembolization with Oxaliplatin Increases Tumor Exposure Compared to Systemic Administration in a Rabbit Model of Hepatocellular Carcinoma
}

\author{
A Dencausse ${ }^{1 *}$, E Laveissiere ${ }^{1}$, JM Idee ${ }^{1}$, C Factor ${ }^{1}$, S Ballet ${ }^{2}$, P Robert ${ }^{1}$, A Seron ${ }^{1}$ and C Corot ${ }^{1}$ \\ ${ }^{1}$ Guerbet, Research \& Innovation Division, BP 57400, 95943 Roissy-Charles de Gaulle cedex, France \\ ${ }^{2}$ Guerbet, Medical Affairs Division, BP 57400, 95943 Roissy-Charles de Gaulle cedex, France
}

*Corresponding author: Anne Dencausse, Guerbet, Research \& Innovation Division, BP 57400, 95943 Roissy-Charles de Gaulle

cedex, France

\section{ARTICLE INFO}

Received: 幽 July 08, 2021

Published: 崽 August 05, 2021

Citation: A Dencausse, E Laveissiere, JM Idee, C Factor, S Ballet, et al., Selective Conventional Transarterial Chemoembolization with Oxaliplatin Increases Tumor Exposure Compared to Systemic Administration in a Rabbit Model of Hepatocellular Carcinoma. Biomed J Sci \& Tech Res 37(5)-2021. BJSTR. MS.ID.006065.

Abbreviations: HCC: Hepatocellular Carcinoma; TACE: Transcatheter Arterial Chemoembolization; OS: Overall Survival; PFS: Progression-Free Survival; cTACE: Conventional TACE; IV: Intravenous; DNA: Deoxyribonucleic Acid; SD: Standard Deviation; DCE-US: Dynamic Contrast-Enhanced Ultrasonography; RECIST: Response Evaluation Criteria in Solid Tumors; mRECIST: Modified RECIST; Pt: Elemental Platinum; ICP-MS: Inductively-Coupled Plasma Mass Spectrometry; HE: Hematoxylin-Eosin; AUC: Area Under the Curve; \%ID/g: Percentage of Injected Dose Per Gram

\section{ABSTRACT}

Purpose: To compare the pharmacokinetics and biodistribution of hepatic artery infusion of oxaliplatin emulsified in Lipiodol (cTACE) versus intravenous (IV) infusion in a rabbit model of HCC.

Materials and Methods: Sixteen VX2 rabbits (4 rabbits/ time of sacrifice) received an IV infusion of oxaliplatin solution ( $4 \mathrm{mg} / \mathrm{kg}$ ). Another 18 rabbits ( 4 or 5 rabbits/ time of sacrifice) received a $0.3 \mathrm{~mL}$ infusion $(0.75 \mathrm{mg} /$ rabbit $)$ of $1: 2$ oxaliplatin:Lipiodol ${ }^{\circledR}$ emulsion followed by Curaspon $\AA$ by hepatic artery infusion, called conventional transarterial chemoembolization (cTACE). Pharmacokinetic analyses were performed on plasma or ultrafiltered plasma. Plasma and tissue samples (healthy liver, tumor, pancreas, spleen, heart, lungs, kidneys) were collected at $1 \mathrm{~h}, 24 \mathrm{~h}, 72 \mathrm{~h}$ and $168 \mathrm{~h}$ after the treatment and analysed by ICP-MS for quantification of elemental platinum (Pt) concentrations. Tumor response was quantified by ultrasound imaging and tumor necrosis was quantified by histology.

Results: While plasma exposure was 11-fold lower after cTACE, mean Pt concentrations in the tumor were higher (cTACE vs IV, mean \pm SD: $24.9 \pm 22.3$ vs $11.3 \pm 8.7 \mathrm{nmol} / \mathrm{g}$ at $1 \mathrm{~h}$ post-administration, $24.6 \pm 22.0$ vs $5.9 \pm 0.9 \mathrm{nmol} / \mathrm{g}$ at $24 \mathrm{~h}, 13.8 \pm 13.4 \mathrm{vs} 3.9 \pm 0.8 \mathrm{nmol} / \mathrm{g}$ at $72 \mathrm{~h}, 18.5 \pm 11.5$ vs $2.5 \pm 0.8 \mathrm{nmol} / \mathrm{g}$ at $168 \mathrm{~h}$ ). The tumor/healthy liver ratio, the most important parameter for the proof-of-concept of tumor targeting with minimal exposure to the liver was close to 1 for the IV route whereas it exceeded 20 , at all times points for cTACE treatment and reached 65 at $168 \mathrm{~h}$. Tumor necrosis (CTACE vs IV) was also significantly higher at 24,72 and 168 post-administration: $92 \pm 17 \%$ vs $45 \pm 5 \%, 99 \pm 3 \%$ vs $47 \pm 15 \%, 96 \pm 8 \%$ vs $41 \pm 19 \%$, respectively.

Conclusion: cTACE using a low dose of oxaliplatin in Lipiodol water-in-oil emulsion resulted in higher Pt concentrations in the tumor, lower systemic exposure and higher tumor necrosis than a higher intravenous dose of oxaliplatin in VX2 rabbits.

\section{Introduction}

The treatment of hepatocellular carcinoma (HCC) is challenging. Traditional antineoplastic agents have shown limited clinical efficacy in advanced stages of HCC, particularly in the context of progression after locoregional therapy such as transcatheter arterial chemoembolization (TACE) [1]. The phase III prospective, randomized EACH trial compared the FOLFOX4 regimen (combining fluorouracil, leucovorin and oxaliplatin by IV administration) 
versus doxorubicin in Asian patients with unresectable HCC who were ineligible for locoregional therapy. Although the primary endpoint of OS benefit with FOLFOX4 did not reach significance at the prespecified end-point, the FOLFOX4 regimen was associated with longer OS compared to doxorubicin (median OS: 6.40 months with FOLFOX4 and 4.97 months with doxorubicin; $p=0.07$, hazard ratio $=0.80(0.63-1.02)$ ). However, PFS, response rate and disease control rate were significantly higher with FOLFOX4 combination therapy than with systemic doxorubicin [2].

A subsequent unplanned analysis performed on the subgroup of Chinese patients showed a median OS at the prespecified treatment time-point of 5.7 months with FOLFOX4 and 4.3 months with doxorubicin (hazard ratio: $0.74 ; 95 \%$ confidence interval: $0.55-0.98 ; p=0.03$ ) [3]. These studies led the Chinese Food and Drug Administration to grant approval for the FOLFOX4 regimen for the treatment of advanced HCC ineligible for surgery [1]. The GEMOX regimen (combining gemcitabine and oxaliplatin) was retrospectively tested in the AGEO trial in 204 patients with advanced HCC with interesting results (PFS of 4.5 months and OS of 11.0 months). However, grade 3-4 toxicity, comprising thrombocytopenia, neutropenia, diarrhea and neurotoxicity, was observed in $44 \%$ of patients and resulted in treatment discontinuation in $16 \%$ of cases [4]. Conventional TACE (CTACE), combining a cytotoxic drug with Lipiodol ${ }^{\circledR}$ Ultra Fluid, an oily contrast medium consisting of a mixture of long-chain diiodinated ethyl esters of fatty acids from poppy seed oil [5] with an additional embolizing agent such as gelfoam, was conceived and first investigated by a Japanese team in 1983 for the treatment of patients with mostly unresectable HCC [6].

TACE has subsequently become the standard of care for the treatment of patients with intermediate stage HCC (Barcelona Clinic Liver Cancer, BCLC stage B) [7]. Recently ESMO also recommended TACE (grade A, level of evidence I) for early stage patients who are in the waiting list for liver transplantation (bridging therapy) based on XXL trial [8]. The most commonly used antineoplastic agents are anthracyclines, (especially doxorubicin or epirubicin), platinum-based agents (cisplatin, oxaliplatin or miriplatin) and mitomycin $\mathrm{C}$ in association with other drugs $[7,9,10]$. As one of the key advantages of TACE is the prolonged high exposure of tumor to the drug, the choice of molecule is of paramount importance, especially as HCC is a highly resistant tumor [1]. Only a few nonclinical comparative studies [11-13] have rigorously investigated the cytotoxic effect of current (or future) antineoplastic molecules. These studies were mostly based on 2D in vitro cytotoxicity models performed on various human or animal cell lines. Cytotoxicity may differ according to the cell line selected [12].

These studies prompted the proposal of drugs such as idarubicin [11], doxorubicin or tyrosine kinase inhibitors [12] for animal and clinical studies. Oxaliplatin forms cross-links with deoxyribonucleic acid (DNA). It mainly forms intra-strand adducts between two adjacent guanine residues or between guanine and adenine, thereby disrupting DNA replication and transcription [14]. Although this phenomenon occurs to a lesser extent with oxaliplatin compared to cisplatin, the adducts more potently inhibit DNA replication [15]. Interestingly, oxaliplatin is cytotoxic in cisplatin-resistant cell lines, including colon adenocarcinoma cells [16]. The oxaliplatin toxicity profile appears to differ from that of cisplatin, with less neutropenia, anemia, thromboembolic events and alopecia, but increased neurotoxicity and diarrhea [17]. We hypothesized that cTACE with Lipiodol and oxaliplatin and a supplementary embolizing agent would:

a) Reduce systemic exposure to the cytotoxic molecule;

b) Improve tumor uptake and

c) Improve pharmacological efficacy, compared with intravenous administration.

The purpose of this study was therefore to compare the pharmacokinetics and biodistribution of oxaliplatin emulsified in Lipiodol supplemented with additional embolizing agent (cTACE procedure) administered by hepatic artery infusion with intravenous (IV) infusion of oxaliplatin in a rabbit model of HCC.

\section{Materials and Methods}

\section{Test Compounds}

Oxaliplatin $50 \mathrm{mg}$ powder for injection (Eloxatin ${ }^{\circledR}$, Sanofi, China) was administered either by intravenous (IV) infusion or by cTACE in the form of a water-in-oil (w/o) emulsion with Lipiodol ${ }^{\circledR}$ Ultra Fluid (Guerbet, Villepinte, France). Oxaliplatin $50 \mathrm{mg}$ powder was dissolved in $10 \mathrm{~mL}$ of water for injection to obtain a $5 \mathrm{mg} / \mathrm{mL}$ solution. For cTACE, oxaliplatin was emulsified by the repeated pumping method (35 back-and-forth pumping) of an aqueous phase (3.3 $\mathrm{mL}$ of a $7.6 \mathrm{mg} / \mathrm{mL}$ oxaliplatin solution) into an oily phase (6.7 $\mathrm{mL}$ Lipiodol ${ }^{\circledR}$ ) using a 3-way stopcock and two $20 \mathrm{~mL}$ syringes. The water-in-oil emulsion [oxaliplatin (final concentration in the emulsion: $2.5 \mathrm{mg} / \mathrm{ml}$ ) -Lipiodol] was prepared extemporaneously and was verified by microscopic examination and by carrying out the drop test [18].

\section{Liver Tumour Model}

All animal experiments were conducted in strict compliance with European Union Directive 2010/63/EU on the protection of animals used for scientific purposes. The protocol was approved by the local animal research ethics committee. All surgeries were performed under general anesthesia and aseptic conditions and were supplemented by appropriate analgesic programs. Liver tumors were induced in 34 female New Zealand white rabbits (3.42 $\pm 0.32 \mathrm{~kg}$, Charles River, Saint-Germain-Nuelles France). One VX2 well-vascularized tumor fragments ( $25 \mathrm{mg}$ ), obtained from a 
carrier animal, was immediately implanted in the left median lobe of the exposed liver of the recipient rabbit. After $19 \pm 1$ or 2 days of tumor growth, tumor size was considered optimal to carry out cTACE (mean \pm SD: diameter of $2.5 \pm 0.6 \mathrm{~cm}$ measured by ultrasound imaging).

\section{Drug Administration}

The oxaliplatin solution was administered at a dose of $4 \mathrm{mg} /$ $\mathrm{kg}$ by intravenous (IV) infusion (marginal ear vein) over 6 minutes. The Insyte catheter $\left(22\right.$ G, Introcan ${ }^{\circledR}-W, B$ Braun, Melsungen, Germany) was then flushed with $1 \mathrm{~mL}$ of $0.9 \% \mathrm{NaCl}$ (CDM Lavoisier, Paris, France). For cTACE, a 4-French guide (Radifocus ${ }^{\circledR}$ Introducer II, Terumo Europe N.V., Leuven, Belgium) was positioned in the rabbit's femoral artery to allow introduction of a 4-French catheter (Outlook ${ }^{\circledR}$, Bolia Mini-Cath, Terumo) to perform angiography (using a mobile $\mathrm{C}$-arm with flat detector, Veradius ${ }^{\circledR}$, Philips, France) to delineate the blood supply to the liver and to confirm the location of the tumor. The iodinated contrast agent administered was iobitridol $300 \mathrm{mgI} / \mathrm{mL}$ diluted to half (Xenetix $300^{\circledR}$, Guerbet, Villepinte, France). Subsequently, a 1.7-French catheter (Echelon ${ }^{\circledR}$, $\mathrm{eV}^{\circledR}{ }^{\circledR}$, Medtronic B.V., Heerlen, The Netherlands) was selectively inserted into the left hepatic artery using an 0.012-inch guide wire (Radifocus ${ }^{\circledR}$, Terumo Europe NV, Leuven, Belgium) and used for emulsion injection. A fixed volume of emulsion $(0.3 \mathrm{~mL} ; 0.75$ $\mathrm{mg} /$ rabbit) was administered by cTACE over 6 minutes, followed by administration of gelatin sponge (Curaspon ${ }^{\circledR}$, CuraMedical B.V., Assendelft, The Netherlands) injected until retrograde flow (variable volume). Gelatin powder was suspended in iobitridol (Xenetix, Guerbet Villepinte, France) to obtain a radiopaque white foam.

\section{Study Groups}

This study was carried out on 34 rabbits divided into 8 groups of 4 to 5 rabbits (Figure1).

\begin{tabular}{|c|c|c|c|c|}
\hline $\begin{array}{c}\text { Group } 1 \\
\mathrm{n}=4 \text { rabbits }\end{array}$ & 1 & $\begin{array}{c}\text { Group } 3 \\
n=4\end{array}$ & 5 & IV \\
\hline $1 \mathrm{H}$ & $24 \mathrm{H}$ & $72 \mathrm{H}$ & $168 \mathrm{H}$ & \multirow{2}{*}{$\begin{array}{l}12-16 \mathrm{mg} \\
\text { oxaliplatin / } \\
\text { rabbit }\end{array}$} \\
\hline$A$ & $\begin{array}{c}\text { Group } 2 \\
\mathrm{n}=4\end{array}$ & $\mathbf{A}$ & $\begin{array}{c}\text { Group } 4 \\
\mathrm{n}=4\end{array}$ & \\
\hline $\begin{array}{c}\text { Group } 5 \\
\mathrm{n}=4\end{array}$ & $V A$ & $\begin{array}{c}\text { Group } 7 \\
\mathrm{n}=4\end{array}$ & $\sqrt{1}$ & \multirow{3}{*}{$\begin{array}{l}\text { CTACE } \\
0.75 \mathrm{mg} \\
\text { oxaliplatin / } \\
\text { rabbit }\end{array}$} \\
\hline \multirow{2}{*}{$1 \mathrm{H}$} & $24 \mathrm{H}$ & $72 \mathrm{H}$ & $168 \mathrm{H}$ & \\
\hline & $\begin{array}{c}\text { Group } 6 \\
\mathrm{n}=5\end{array}$ & A & $\begin{array}{c}\text { Group } 8 \\
n=5\end{array}$ & \\
\hline
\end{tabular}

Figure 1: Distribution diagram of the 34 rabbits in the 8 groups of the study.

\section{Tumour Response}

In all test groups, ultrasound imaging (B mode) and dynamic contrast-enhanced (DCE) mode with sulfur hexafluoride microbubbles (Sonoview ${ }^{\circledR}$, Bracco Diagnostics, Milano, Italy) was performed (Aixplorer ${ }^{\circledR}$, Supersonic Imaging, Aix-en-Provence, France) before treatment and 30 minutes before necropsy to measure the size (longest diameter) (Response Evaluation Criteria in Solid Tumors, RECIST criteria) (NDP View 2.0 software). The intratumoral arterial phase enhancement, reflecting tumor perfusion of viable areas (modified RECIST criteria, mRECIST) was measured in an all (enhancement during the arterial phase) -ornothing (enhancement during the portal phase) manner by DCEUS.

\section{Protocol}

For groups 2 and 6, blood samples were drawn from the auricular artery at 2, 5, 10, 20, 30 minutes and 1, 2, 3, 4, 5, 6, and 24 hours following the start of administration for pharmacokinetic analyses (elemental platinum (Pt) measurement). Blood was centrifuged $\left(3,500 \mathrm{~g}, 10 \mathrm{~min}, 4^{\circ} \mathrm{C}\right)$ and then ultrafiltered $(2,000 \mathrm{~g}$, 22 min, $25^{\circ} \mathrm{C}$, Centrifree ${ }^{\circledR}$, Merck KGaA, Darmstadt, Germany) to obtain $100 \mu \mathrm{L}$ samples of protein-free ultrafiltered plasma. The same for groups 4 and 8, blood samples were drawn from the auricular artery at 1, 2, 3, 4, 5, 6 and 24 hours and then once daily until day 7 (except on the weekend). Blood was centrifuged $(3,500$ g, $10 \mathrm{~min}, 4^{\circ} \mathrm{C}$ ) to obtain plasma. 
At the time of each group, rabbits were sacrificed by bolus administration of pentobarbital sodium (Dolethal ${ }^{\circledR}$, Vetoquinol). Blood was drawn for all groups and was centrifuged (3,500 g, 10 $\min , 4^{\circ} \mathrm{C}$ ). For all groups, plasma, one half of the tumor, right lobe of liver, lung, kidney, pancreas, spleen and heart were sampled for quantification of elemental Pt concentrations by inductively coupled plasma mass spectrometry (ICP-MS) (7,700x, Agilent Technologies, Santa Clara, CA). The Pt concentrations obtained were then converted to wet tissue concentrations (nmol Pt/g) considering all dilution steps. The areas under the tissue concentration-time curve (AUC-last) were calculated by the trapezoidal method from 0 to the last experimental time-point to compare tissue exposure to oxaliplatin.

The other half of the tumor was fixed with $4 \%$ formalin and used for blinded histological examination after hematoxylin-eosin (H\&E) staining. Tumor necrosis, expressed as a percentage of the whole tumor area, was measured using NDP View 2.0 software (Hamamatsu Photonics K.K., Hamamatsu City, Japan). The following tumor budding scoring was used: $0=$ no viable tumor buds; $1=$ rare small viable buds (islets composed of a few cells), small buds (isolated islets); 2 = small number of tumor buds; 3 = moderate to numerous tumor buds. "Buds" were defined as clusters of living tumor cells.

\section{Statistical Analysis}

The Mann-Whitney test was performed to compare, for example, the percentage of injected dose per gram (\%ID/g) of organs or the Pt concentrations in organs, at each time of sacrifice, between the two routes of administration, based on the results of a prior Kruskal-Wallis test by ranks. These tests do not consider multiplicity and therefore cannot be considered to test the inference (extrapolation to the whole population) and significance levels are purely descriptive. Analyses were performed with GraphPad Prism 8 software (GraphPad Software Inc., La Jolla, CA, USA). A significance level of $5 \%$ was adopted.

\section{Results}

\section{Pharmacokinetic Analysis}

Total Plasma Platinum Decay and Body Exposure: Total plasma Pt decay profiles indicate lower systemic exposure to oxaliplatin in the cTACE group compared to the IV group (Figure 2 ), which was confirmed by calculating the area under the plasma concentration-time curve (AUC), as the $\mathrm{AUC}_{0 \text {-last }}$ was 11-fold lower in the cTACE group than in the IV oxaliplatin group (Figure 3).

Ultrafiltered Plasma Platinum Decay and Body Exposure: Decay patterns in ultrafiltered protein plasma also indicate significantly lower systemic exposure to unbound Pt in the cTACE group compared to the IV group. (Figure 4).

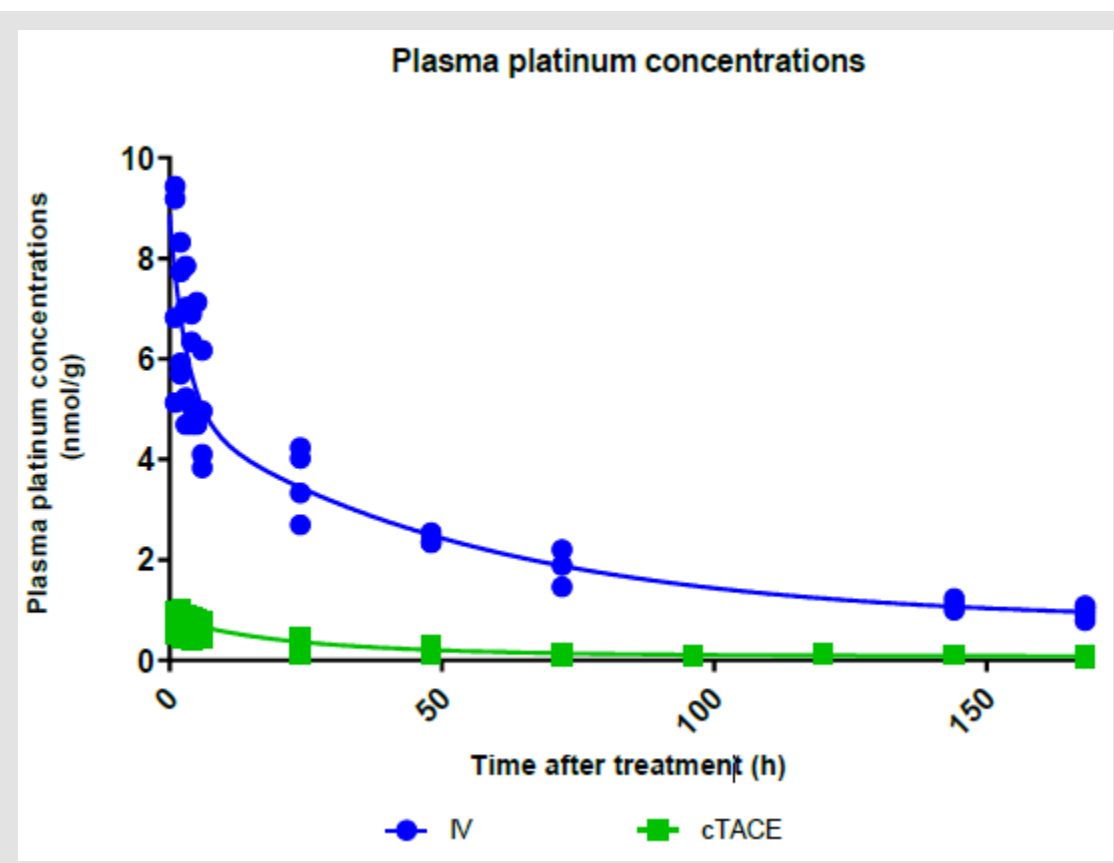

Figure 2: Plasma decay profiles of total Pt concentrations over time following IV or cTACE oxaliplatin treatments to rabbits bearing a VX2 liver tumor. Data are shown as individual values. 


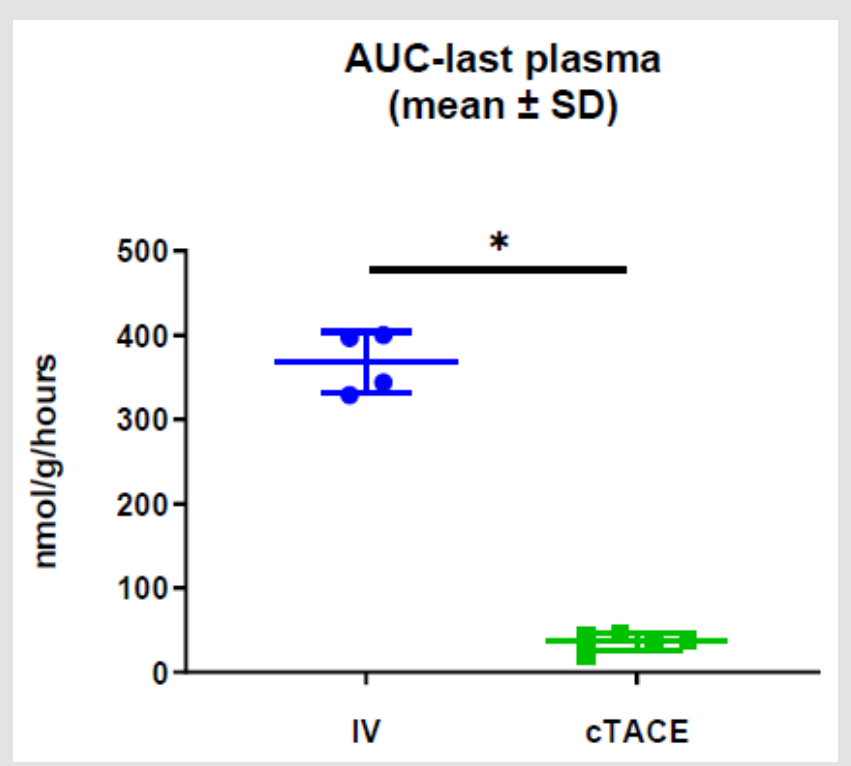

Figure 3: Area under the curve (AUC) from time of administration to 7 days calculated from plasma Pt concentrations. Data are shown as mean \pm SD and individual values $\left({ }^{*}=p<0.05\right)$.

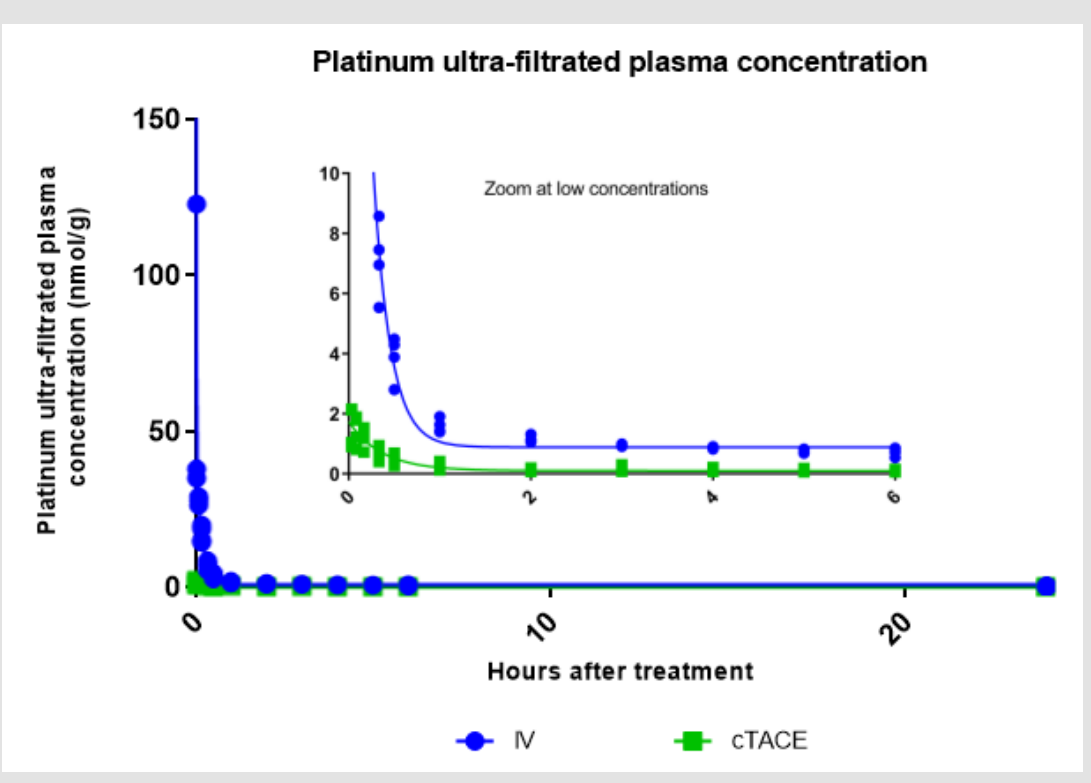

Figure 4: Plasma decay profiles of protein-free ultrafiltered plasma Pt concentrations over the first 24 hours following IV or cTACE oxaliplatin treatments to rabbits bearing a VX2 liver tumor. The inset shows a zoom at low Pt concentrations Data are shown as individual values.

\section{Tumour Platinum Distribution}

Regardless of the time-point considered, the mean percentage of the injected dose of oxaliplatin per gram of tumor (\%ID/g) was significantly higher in the cTACE groups than in the IV groups
(Table 1). Mean Pt concentrations in the VX2 tumor were also higher, but not significantly. There was no statistical evidence for a time-dependant decrease in Pt concentrations (Figure 5). Marked variability was observed within the cTACE groups. VX2 tumor targeting was considered weak in 3 out of 18 rabbits. 


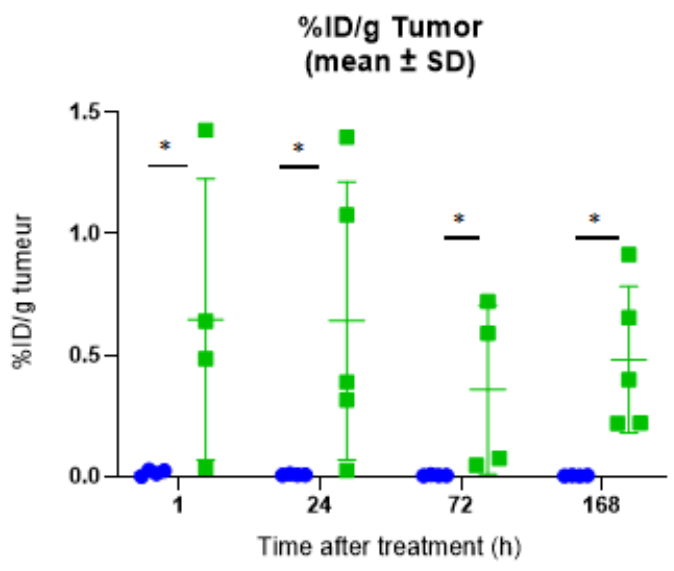

- IV

\section{Concentration of Pt in tumors (mean \pm SD)}

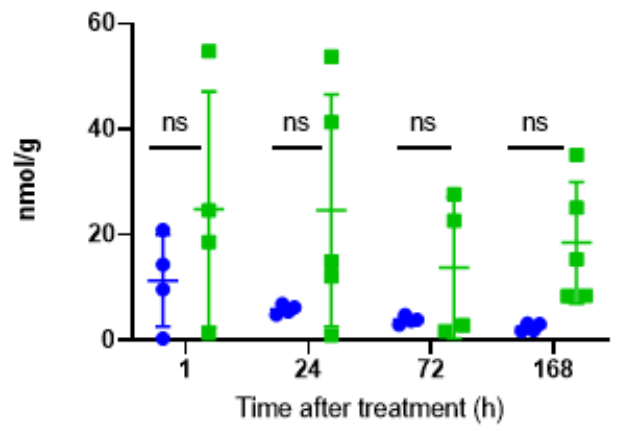

- CTACE

Figure 5: Percentage of injected dose of oxaliplatin per gram of VX2 tumor and Pt concentration in the VX2 tumor at the various experimental time-points following either intravenous (12-16 mg oxaliplatin / rabbit) or selective intra-tumoral administration ( $0.75 \mathrm{mg}$ oxaliplatin / rabbit) to VX2 rabbits. Data are shown as mean $\pm \mathrm{SD}$ and individual values. NS $=$ non significant, * $=$ $\mathrm{p}<0.05$.

Table 1: Pt concentration in the tumor and healthy liver tissue, percentage of injected dose of oxaliplatin per gram of organ and tumor/ healthy liver tissue ratio at the various experimental time-points following cTACE $(0.75 \mathrm{mg}$ oxaliplatin/ rabbit) or IV administration (12-16 mg oxaliplatin / rabbit) to VX2 rabbits.

\begin{tabular}{|c|c|c|c|c|c|c|}
\hline \multirow{2}{*}{\multicolumn{2}{|c|}{ Delay }} & \multicolumn{2}{|c|}{ Tumor } & \multicolumn{2}{|c|}{ Healthy liver } & \multirow{3}{*}{$\begin{array}{c}\begin{array}{c}\text { Tumor/ healthy } \\
\text { liver ratio }\end{array} \\
0.82 \pm 0.47\end{array}$} \\
\hline & & \multirow{2}{*}{$\begin{array}{c}\mathbf{n m o l} / \mathbf{g} \\
11.3 \pm 8.7\end{array}$} & \multirow{2}{*}{$\begin{array}{c}\text { \%ID/g } \\
0.016 \pm 0.012 \\
\end{array}$} & \multirow{2}{*}{$\begin{array}{c}\mathbf{n m o l} / \mathbf{g} \\
16.5 \pm 12.2 \\
\end{array}$} & \multirow{2}{*}{$\begin{array}{c}\% \mathbf{I D} / \mathbf{g} \\
0.023 \pm 0.017 \\
\end{array}$} & \\
\hline la & IV & & & & & \\
\hline 111 & cTACE I & $24.9 \pm 22.3(\mathrm{NS})$ & $0.65 \pm 0.58(*)$ & $1.3 \pm 0.3\left(^{*}\right)$ & $0.034 \pm 0.008$ (NS) & $22 \pm 21(\mathrm{NS})$ \\
\hline \multirow{2}{*}{$24 \mathrm{~h}$} & IV & $5.9 \pm 0.9$ & $0.008 \pm 0.002$ & $6.9 \pm 1.7$ & $0.009 \pm 0.004$ & $0.87 \pm 0.17$ \\
\hline & cTACE & $24.6 \pm 22.0$ (NS) & $0.65 \pm 0.57\left({ }^{*}\right)$ & $0.5 \pm 0.1(* *)$ & $0.014 \pm 0.002(\mathrm{NS})$ & $45 \pm 37(*)$ \\
\hline \multirow{2}{*}{$72 \mathrm{~h}$} & IV & $3.9 \pm 0.8$ & $0.006 \pm 0.002$ & $5.9 \pm 2.0$ & $0.008 \pm 0.003$ & $0.71 \pm 0.27$ \\
\hline & cTACE & $13.8 \pm 13.4(\mathrm{NS})$ & $0.36 \pm 0.35\left(^{*}\right)$ & $0.5 \pm 0.4\left(^{*}\right)$ & $0.014 \pm 0.011$ (NS) & $35 \pm 32(*)$ \\
\hline \multirow{2}{*}{$168 \mathrm{~h}$} & IV & $2.5 \pm 0.8$ & $0.003 \pm 0.00\left(^{*}\right)$ & $4.2 \pm 1.8$ & $0.006 \pm 0.003$ & $0.67 \pm 0.27$ \\
\hline & cTACE & $18.5 \pm 11.5(\mathrm{NS})$ & $0.48 \pm 0.30\left(^{*}\right)$ & $0.3 \pm 0 . \mathrm{I}(*)$ & $0.008 \pm 0.002(\mathrm{NS})$ & $65 \pm 42(*)$ \\
\hline
\end{tabular}

Data are shown as mean $\pm \mathrm{SD}, \mathrm{NS}=$ non signifiant, ${ }^{*}=\mathrm{p}<0.05,{ }^{* *}=\mathrm{p}<0.01$.

\section{Platinum Distribution in Healthy Liver Parenchyma}

The Pt distribution in the healthy liver was very low (the percentage of injected dose per gram of healthy liver tissue was less than $0.05 \%$ /g at 1 hour for both groups) (Table 1). Overall, no significant difference of the percentage of injected dose per gram was observed between the IV and cTACE routes of administration. On the other hand, a significantly much lower exposure at 24, 72 and $168 \mathrm{~h}$ was observed after cTACE injection due to the lower dose injected. Pt concentrations decreased as a function of time, in contrast with tumor Pt concentrations, due to elimination by the kidneys (Figure 6).

\section{Tumor/Healthy Liver Ratio}

The most important parameter for the proof-of-concept of tumor targeting with minimal exposure to the liver is the tumor/ healthy liver ratio (Figure 7). Despite the variability of data in the cTACE group, which minimizes differences between the two groups, the ratio was close to 1 for the IV route (Table 1), whereas it exceeded 20, at all times points for cTACE treatment and reached 65 at $168 \mathrm{~h}$ (Table 1$)$. 


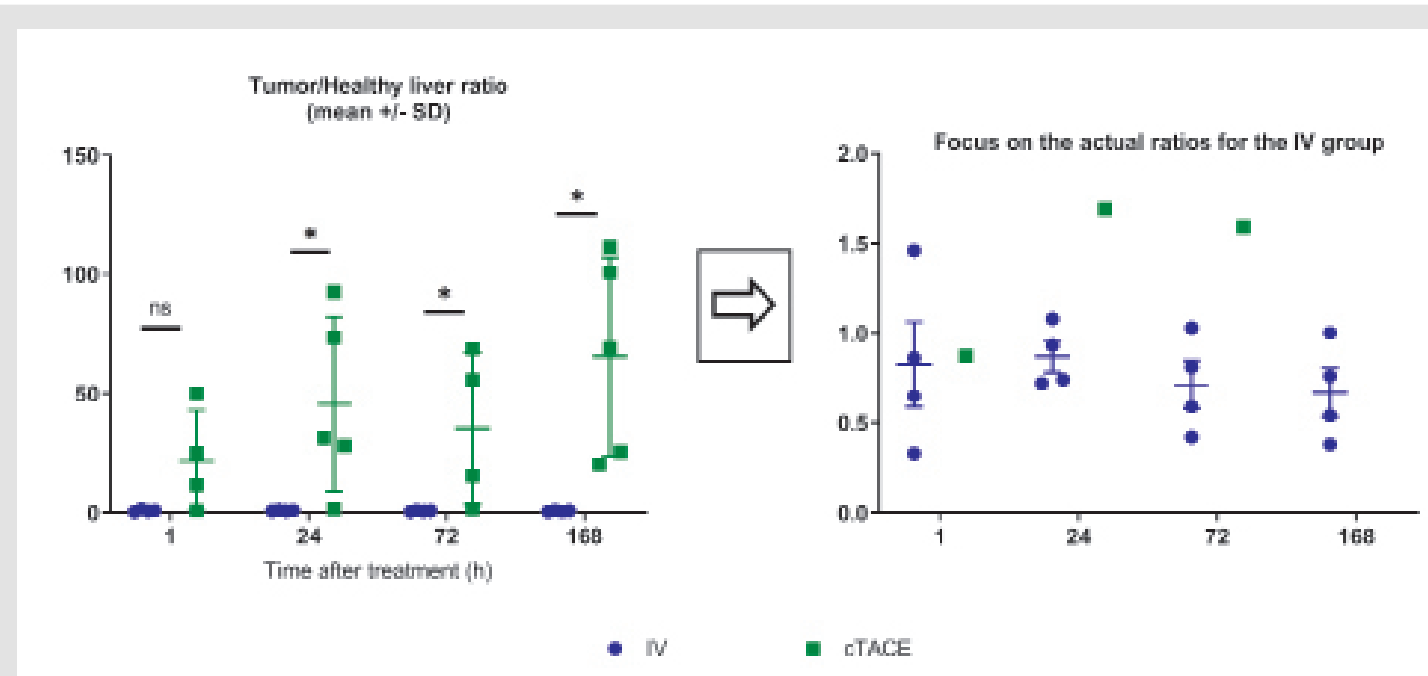

Figure 6: Percentage of injected dose of oxaliplatin per gram of healthy liver and Pt concentration in the healthy liver at the various experimental time-points following either intravenous (12-16 mg oxaliplatin / rabbit) or selective intra-tumoral administration $(0.75 \mathrm{mg}$ oxaliplatin / rabbit) to VX2 rabbits. Data are shown as mean $\pm \mathrm{SD}$ and individual values NS $=$ non significant, ${ }^{*}=\mathrm{p}<0.05,{ }^{* *}=\mathrm{p}<0.01$.

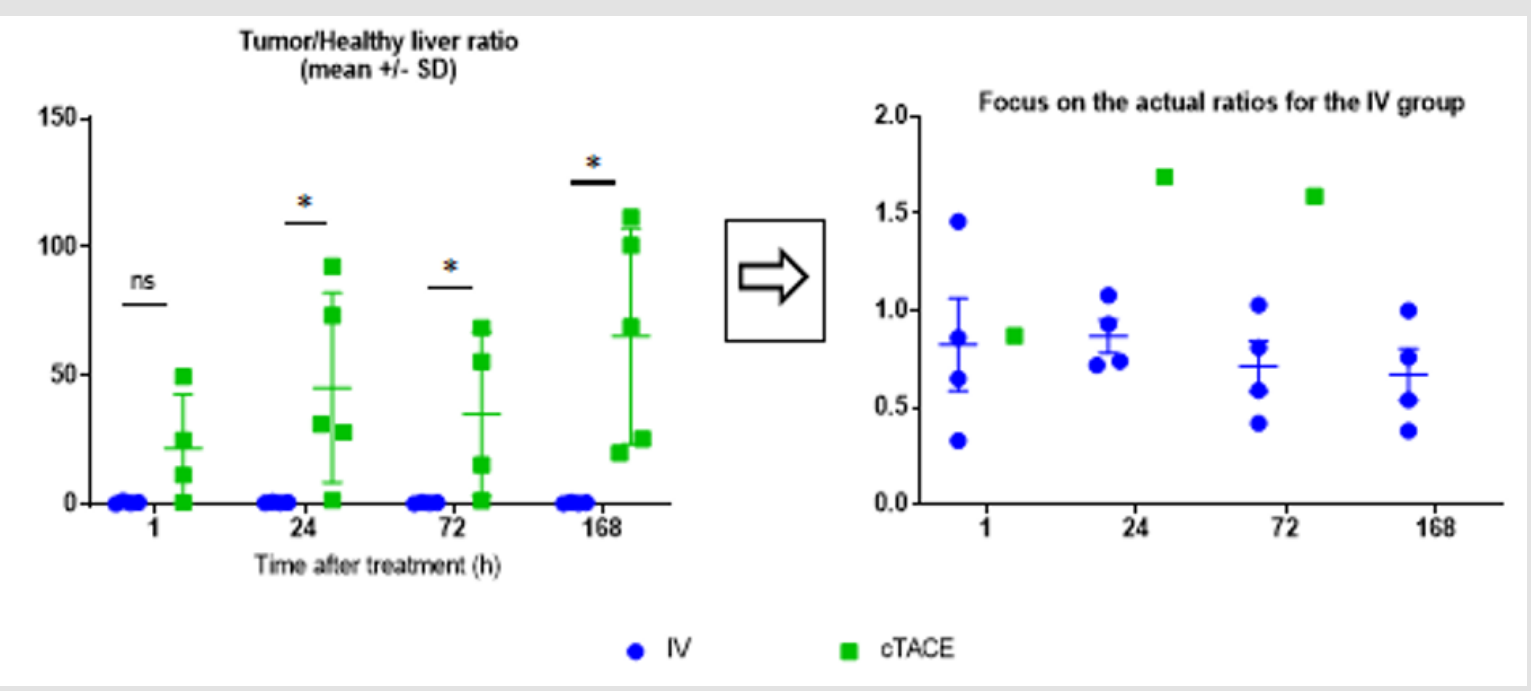

Figure 7: Tumor/healthy liver tissue ratio (the inset focuses on the actual ratios for the IV group).

Data are shown as mean \pm SD and individual values. NS $=$ non significant, ${ }^{*}=p<0.05$.

Table 2: Pt concentration in organs (pancreas, spleen, lung, heart and kidney) and percentage of injected dose of oxaliplatin per gram of organ at the various experimental time-points following either intravenous (12 $16 \mathrm{mg}$ oxaliplatin / rabbit) or selective intratumoral administration ( $0.75 \mathrm{mg}$ oxaliplatin / rabbit) to VX2 rabbits.

\begin{tabular}{|c|c|c|c|c|c|c|c|c|c|c|c|}
\hline & & \multicolumn{2}{|c|}{ Pancreas } & \multicolumn{2}{|c|}{ Spleen } & \multicolumn{2}{|c|}{ Lung } & \multicolumn{2}{|c|}{ Heart } & \multicolumn{2}{|c|}{ Kidney } \\
\hline \multicolumn{2}{|c|}{ Delay } & $\mathrm{nmol} / \mathrm{g}$ & $\% \mathrm{ID} / \mathrm{g}$ & $\mathrm{nmol} / \mathrm{g}$ & $\% \mathrm{ID} / \mathrm{g}$ & $\mathrm{nmol} / \mathrm{g}$ & $\% I D / g$ & $\mathrm{nmol} / \mathrm{g}$ & $\% \mathrm{ID} / \mathrm{g}$ & $\mathrm{nmol} / \mathrm{g}$ & $\% \mathrm{ID} / \mathrm{g}$ \\
\hline \multirow[t]{2}{*}{ lh } & IV & $4.7 \pm 3.29$ & $0.007 \pm 0.005$ & $13.91 \pm 9.20$ & $0.020 \pm 0.013$ & $11.91 \pm 8.74$ & $0.017 \pm 0.011$ & $8.95 \pm 5.81$ & $0.013 \pm 0.008$ & $33.1 \pm 21.1$ & $0.047 \pm 0.031$ \\
\hline & cTACE & $0.41 \pm 0.10(\mathrm{NS})$ & $0.011 \pm 0.003(\mathrm{NS})$ & $1.01 \pm 0.44(\mathrm{NS})$ & $0.026 \pm 0.011(\mathrm{NS})$ & $1.45 \pm 0.91(\mathrm{NS})$ & $0.038 \pm 0.024(\mathrm{NS})$ & $0.79 \pm 0.22(\mathrm{NS})$ & $0.021 \pm 0.006(\mathrm{NS})$ & $8.2 \pm 3.2(\mathrm{NS})$ & $0.213 \pm 0.084\left(^{*}\right)$ \\
\hline \multirow{2}{*}{$24 \mathrm{~h}$} & IV & 3. $36 \pm 0.46$ & $0.005 \pm 0.001$ & $10.02 \pm 1.19$ & $0.013 \pm 0.003$ & $7.29 \pm 1.49$ & $0.010 \pm 0.003$ & $5.48 \pm 0.83$ & $0.007 \pm 0.002$ & $19.6 \pm 5.0$ & $0.027 \pm 0.011$ \\
\hline & cTACE & $0.23 \pm 0.13(*)$ & $0.006 \pm 0.003(\mathrm{NS})$ & $0.68 \pm 0.25\left(^{*}\right)$ & $0.018 \pm 0.006(\mathrm{NS})$ & $0.54 \pm 0.23(*)$ & $0.014 \pm 0.006$ (NS) & $0.35 \pm 0.13(*)$ & $0.009 \pm 0.003$ (NS) & $2.7 \pm 1.6(*)$ & $0.069 \pm 0.042\left(^{*}\right)$ \\
\hline \multirow{2}{*}{$72 \mathrm{~h}$} & IV & $2.86 \pm 0.70$ & $0.004 \pm 0,001$ & $11.35 \pm 2.28$ & $0.016 \pm 0.003$ & $7.14 \pm 0.69$ & $0.010 \pm 0.001$ & $5.11 \pm 0.61$ & $0.007 \pm 0.001$ & $23.0 \pm 3.9$ & $0.033 \pm 0.009$ \\
\hline & cTACE & $0.20 \pm 0.06(*)$ & $0.005 \pm 0.002(\mathrm{NS})$ & $0.73 \pm 0.29\left(^{*}\right)$ & $0.019 \pm 0.007$ (NS) & $0.34 \pm 0.14\left({ }^{*}\right)$ & $0.009 \pm 0.004$ (NS) & $0.33 \pm 0.11\left(^{*}\right)$ & $0.009 \pm 0.003(\mathrm{NS})$ & $1.8 \pm 0.8\left(^{*}\right)$ & $0.047 \pm 0.020(\mathrm{NS})$ \\
\hline
\end{tabular}




\begin{tabular}{|c|c|c|c|c|c|c|c|c|c|c|c|}
\hline \multirow{2}{*}{$168 \mathrm{~h}$} & IV & $1.91 \pm 0.75$ & $0.003 \pm 0.001$ & $6.94 \pm 2.13$ & $0.009 \pm 0.003$ & $3.51 \pm 0.76$ & $0.005 \pm 0.001$ & $3.44 \pm 1.00\left(^{*}\right)$ & $0.005 \pm 0.001$ & $14.2 \pm 2.5$ & $0.019 \pm 0.004$ \\
\hline & cTACE & $0.16 \pm 0.05\left(^{*}\right)$ & $0.004 \pm 0.001(\mathrm{NS})$ & $0.58 \pm 0.12(*)$ & $0.015 \pm 0.003(\mathrm{NS})$ & $0.26 \pm 0.06\left(^{*}\right)$ & $0.007 \pm 0.002$ (NS) & $0.23 \pm 0.07\left(^{*}\right)$ & $0.006 \pm 0.002$ (NS) & $1.3 \pm 0.2(*)$ & $0.034 \pm 0.005( \pm)$ \\
\hline
\end{tabular}

Data are shown as mean $\pm S D, N S=$ non significant, ${ }^{*}=p<0.05$.

\section{Platinum Distribution in Other Organs}

Regardless of the organ (pancreas, spleen, lung and heart) and the time-point considered (Table 2), the mean percentage of injected oxaliplatin dose per gram of tissue was low after both routes of administration. No significant difference was observed between the two routes of administration. On the other hand, as in healthy liver, significantly $(\mathrm{p}<0.05)$ much lower exposure was observed at 24-, 72- and 168-hours after the cTACE injection due to the lower dose injected. In the kidney (Table 2), the percentage of Pt concentration per gram of tissue was slightly higher in the cTACE group than in the IV group at 1, 72- and 168-hours postadministration. As in other organs, a significantly $(\mathrm{p}<0.05)$ lower exposure was observed at 24, 72- and 168hours.

\section{Changes in Tumour Size and Blood Perfusion Over Time}

Overall, no significant difference in the percentage change of tumor size (RECIST criterion) following drug administration was observed between the IV and cTACE groups $(2.5 \pm 22.4 \%$ vs $-1.0 \pm 1.2 \%$ at $1 \mathrm{~h}, 12.3 \pm 6.8 \%$ vs $14.0 \pm 23.6 \%$ at $24 \mathrm{~h},-8.0 \pm 11.5 \%$ vs $22.8 \pm 22.2 \%$ at $72 \mathrm{~h}, 39.7 \pm 58.6 \%$ vs $27.5 \pm 34.0 \%$ at $168 \mathrm{~h}$, respectively) (Figure 8). On the other hand, intratumoral enhancement, reflecting tumor viability (mRECIST criterion), evaluated by DCE-US, revealed the absence of tumor perfusion in all but two rabbits in the cTACE group ( $1 \mathrm{~h}$ and $24 \mathrm{~h}$ time-points) strongly suggesting high tumor necrosis rate, while tumor perfusion was maintained in all but one rabbit (24 h time-point) in the IV group suggesting a remaining high viable tumor rate following this treatment.

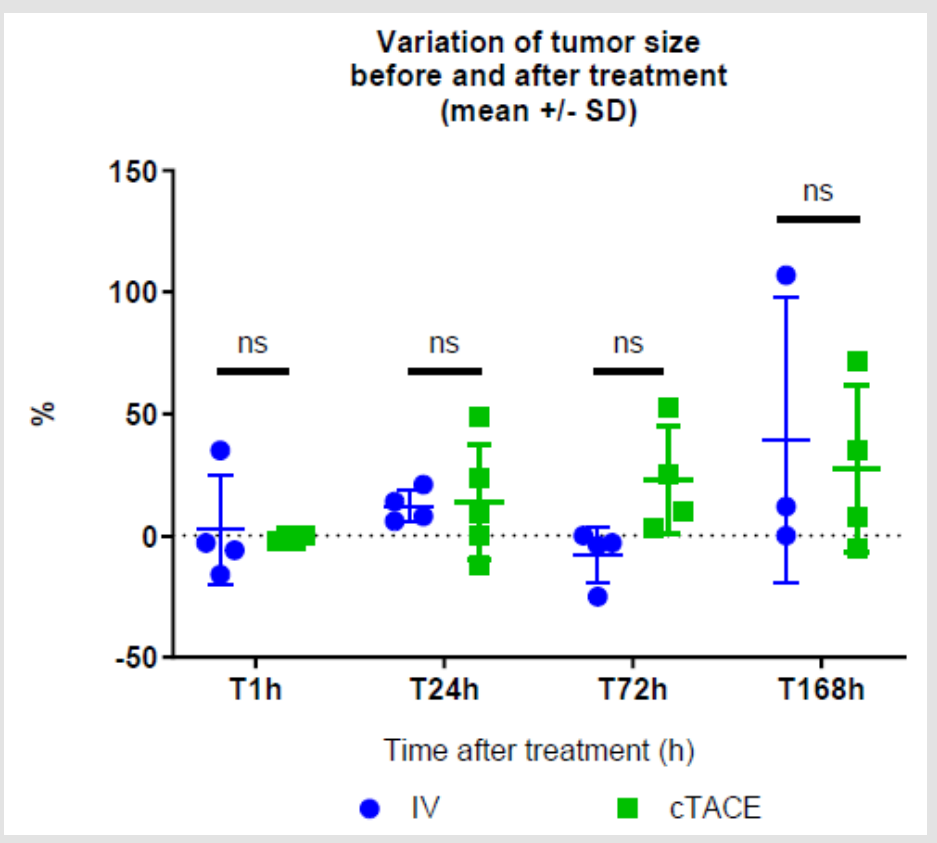

Figure 8: Changes in VX2 tumor size (\%, post- vs. pre-) in the IV and CTACE oxaliplatin groups.

Data are shown as mean \pm SD and individual values. NS $=$ non significant.

\section{Tumor Necrosis}

One-hour post-treatment, central tumor necrosis (around $40 \%$ of the tumor area) was detected in all animals. At 1-, 3- and 7-days post-treatment, no obvious increase in tumor necrosis was observed for any of the animals treated by the IV route. Conversely, in the cTACE group, mean tumor necrosis was greater than $90 \%$ of VX2 tumor area at the 1-, 3- and 7-day time-points. At these 3 timepoints, the percentage of tumor necrosis was significantly higher in the cTACE group than in the IV group (Figure 9). No massive (> 99\%) tumor necrosis was observed in the IV group, regardless of the time-point (Figure 10). In contrast, massive tumor necrosis was commonly observed in the cTACE group at late time-points (1h: 0/4 rabbits; 1 day: 4/5 rabbits; 3 days: 3/4 rabbits and 7 days: 3/4 rabbits) (Figure 11). However, in the cTACE group, viable tumor buds were still observed in 8 out the 10 rabbits with massive necrosis (score $1=$ rare small viable buds (islets of a few cells), small buds (isolated islets): $6 / 8$ animals, score $2=$ small number of tumor buds: $1 / 8$ animal and score $3=$ moderate to numerous tumor buds: $1 / 8$ rabbit). These buds were mostly found at the periphery of the tumor. 


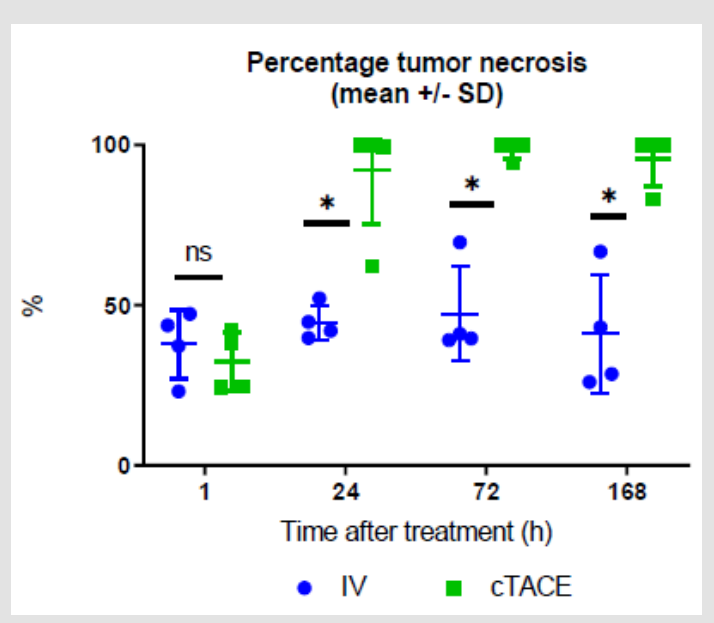

Figure 9: Percentage of tumor necrosis at the various experimental time-points following either intravenous or selective intratumoral administration to VX2 rabbits. Data are shown as mean \pm SD and individual values. NS $=$ non significant, ${ }^{*}=p<0.05$.

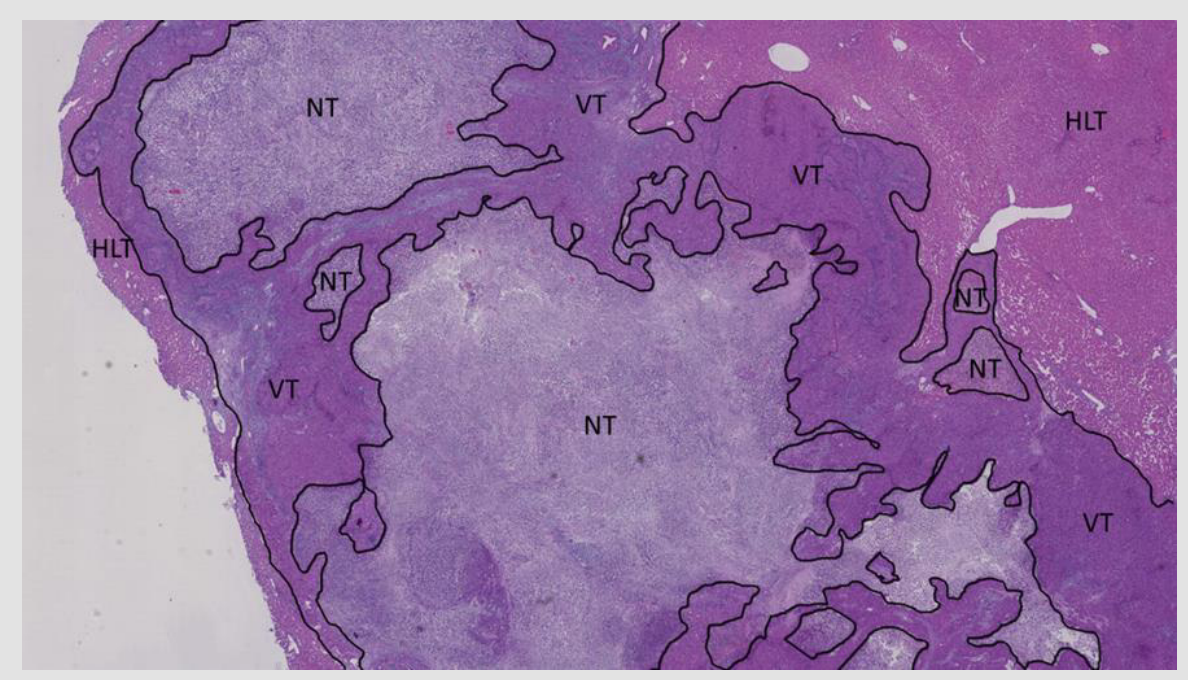

Figure 10: Histological section of the tumor of an IV-treated rabbit $24 \mathrm{~h}$ post-administration NT $=$ necrotic tumor, VT $=$ viable tumor and HLT $=$ healthy liver tissue.

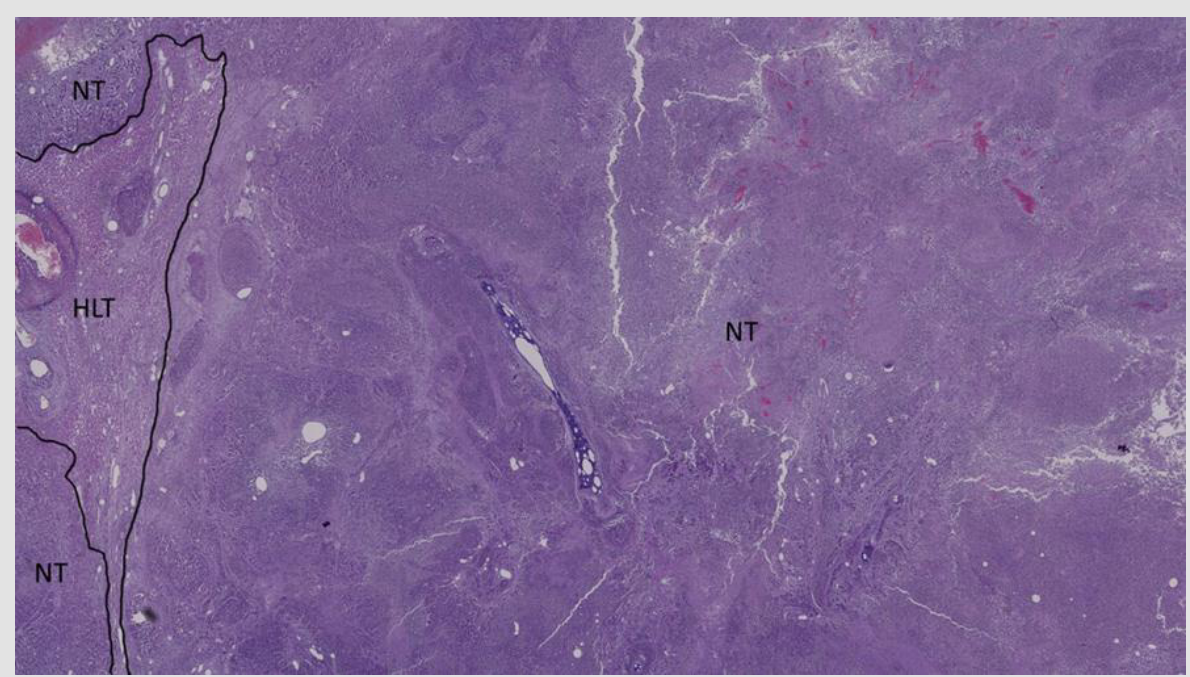

Figure 11: Histological section of the tumor of a cTACE-treated rabbit 24h post-administration NT = necrotic tumor and HLT = healthy liver tissue. 


\section{Safety}

No signs of neurologic or other toxicity were observed in the animals during housing, regardless of the group or the time-point.

\section{Discussion}

Oxaliplatin, in combination with 5-fluorouracil and leucovorin, is widely used for the adjuvant treatment of advanced colorectal cancer [19]. Hepatic arterial infusion of oxaliplatin associated with intravenous administration of leucovorin and 5-fluorouracil has provided promising results after failure of systemic chemotherapy in patients with unresectable liver metastases from colorectal cancer [20]. Conventional TACE combining oxaliplatin and 5 -fluorouracil for the treatment of large $(>10 \mathrm{~cm})$ HCC has been reported, with interesting results (median overall survival and time-to-progression of 10.3 and 3.0 months, respectively) [21]. To our knowledge, no studies have yet compared the clinical efficacy and safety of intravenous and locally administered oxaliplatin at relevant doses in a clinically relevant model of HCC.

The recommended oxaliplatin dose in patients is $85 \mathrm{mg} / \mathrm{m}^{2}$ by intravenous infusion (Eloxatin SPCs) [22]. Assuming a total body surface area of $1.73 \mathrm{~m}^{2}$ and a bodyweight of $80 \mathrm{~kg}$, the human dose would equate to $1.8 \mathrm{mg} / \mathrm{kg}$. In this study, an oxaliplatin dose of $4 \mathrm{mg} /$ $\mathrm{kg}$ was selected. After adjustment for body surface area, by applying a 3.1 ratio, this would equate to a dose of $1.3 \mathrm{mg} / \mathrm{kg}$ in patients, a value close to the recommended dose. In the present study, the oxaliplatin solution and emulsion were infused at different doses ( 4 $\mathrm{mg} / \mathrm{kg}$ for IV infusion versus $0.75 \mathrm{mg} /$ rabbit for cTACE). For cTACE, we deliberately administered a fixed dose of oxaliplatin instead of a bodyweight-dependent dose. This protocol was selected in order to allow subsequent complementary gelfoam embolization, in line with routine cTACE practice in the clinical settting. The difference in administered doses of oxaliplatin explains the higher total plasma Pt concentrations measured in the IV group.

Filterable Pt plasma curves were also measured. Platinum binding to plasma proteins (mostly albumin and gamma globulins) has been demonstrated [23], with $85-88 \%$ of all Pt bound to circulating proteins within 5 hours in patients [24]. Platinum also binds irreversibly to erythrocytes $(15 \%$ in humans, not measured in this study). It is also taken up by peripheral lymphocytes, where it targets DNA [23]. Only unbound Pt is thought to be pharmacologically active [25]. Once again, systemic exposure to the pharmacologically active fraction is much lower via the cTACE route than via the standard route IV.

Interestingly, despite the dramatically lower dose injected during the cTACE procedure, the percentages of injected oxaliplatin dose per gram of tumor were significantly higher after cTACE than after IV injection. Absolute Pt concentrations in tumor tissue were also higher, but not significantly, after cTACE. There was no statistical evidence for a decrease in tumor tissue Pt concentrations over time after cTACE, suggesting that the VX2 tumor constitutes a deep compartment for Pt distribution, which consequently does not follow the Pt elimination profile observed in other tissues. These persistent Pt concentrations in tumor tissue would be clinically relevant, as long-lasting intratumor exposure, while minimizing systemic exposure to the pharmacologically active drug, remains the ultimate goal of cTACE [26]. The results of the present study show that the very low exposure of the healthy hepatic parenchyma as well as the very high tumor concentration contribute to the excellent tumor / healthy liver tissue ratio observed with cTACE, highlighting the benefits associated with the cTACE route of administration of oxaliplatin. A low distribution of oxaliplatin was found in the pancreas, lung, spleen and heart, regardless of the test groups, which was an expected finding. However, the percentage of injected dose per gram of tissue was higher in the kidneys than in these various organs, which is consistent with the predominant renal excretion of oxaliplatin in rabbits [27] and in humans [23] and the results of another comparative IV vs. cTACE study in VX2 rabbits [28]. In a similar VX2 rabbit model, De Baere et al. showed that water-in-oil emulsions containing large droplets of watersoluble cytotoxic drug resulted in lower lung uptake and higher tumor uptake than any other type of Lipiodol-based emulsion [29]. Conventional TACE was therefore performed using a water-in-oil emulsion of oxaliplatin in Lipiodol.

Overall, the IV and cTACE groups were not significantly different in terms of the effects of treatment on tumor diameter, regardless of the time-point. However, the variability of ultrasound examination (estimated at 30\% from in-house studies), the difficulty of positioning the transducer exactly over the same position before and after treatment and the necrosis observed in the cTACE group make it difficult to draw any definite conclusions concerning this parameter.

In patients, HCC tumor viability is estimated on the basis of changes in tumor arterial enhancement after TACE and is quantified by the mRECIST approach. The mRECIST criteria [30] were developed for locoregional therapies for HCC, especially TACE, by incorporating the concept of viable tumor tissue showing uptake during the arterial phase of contrast-enhanced imaging procedures [31]. In the present and non-clinical version of this approach, a complete response was observed in all animals at the end of the study (7 days). Blinded histologic examination of the VX2 tumors was also performed at various time-points. Regardless of the groups, VX2 tumor necrosis was observed in the animals sacrificed at the 1-hour time-point. This tumor necrosis was probably spontaneous, as commonly described in the VX2 rabbit model [32], and unrelated to treatment. At 1-, 3- and 7-days post-treatment, no increase of tumor necrosis was observed for any of the animals treated by IV infusion. In contrast, in the cTACE group, a significant difference 
in the percentage of tumor necrosis was observed between $1 \mathrm{~h}$ versus 1 -, 3 - and 7-days post-treatment $(\mathrm{p}=0.02)$. Massive necrosis (>99\%) was observed in 10/17 tumors treated by cTACE, which can be considered to be a marker of curative treatment. Tumor necrosis was enhanced by the fact that cTACE effectively blocked tumor perfusion at all time-points, in contrast with the IV route.

Viable nodules (score $1 / 3 n=6$; score $2 / 3 n=1$; score $3 / 3 n=1$ ) were still present in $8 / 10$ rabbits, which indicates a risk of tumor progression. The tumor regions that remained morphologically viable were mainly located in the hepatic capsule at the periphery of the tumor. However, a fixed volume of $0.3 \mathrm{~mL}$ of emulsion was administered. Depending on the size/volume of each tumor, tumor Lipiodol uptake may have been only partial, while best clinical practice would require the injection of a volume of Lipiodol-based emulsion until opacification of the arterial-portal vascular bed is observed, in order to ensure effective cTACE [33].

The toxicity of Pt-based chemotherapy is well known. Firstly, Pt analogs, including oxaliplatin, can induce serious and dose-limiting peripheral neurotoxicity [34]. No signs of neurologic toxicity were observed in our study. The favourable dose-efficacy ratio observed in the cTACE group compared with the IV group constitutes a major advantage of this approach, including in terms of safety.

This study has several limitations. Elemental Pt was measured instead of the parent drug or one of the transient metabolites. The dosage of the parent drug or one of the transient metabolites is not technically feasible for pharmacokinetic studies and monitoring of Pt instead of the parent molecule or a metabolite is considered to be an acceptable alternative [23]. Platinum excretion was not assessed by urine assays, as this was not one of the objectives of this study and the renal clearance of oxaliplatin in rabbits has been extensively studied elsewhere [27]. Tumor necrosis was not investigated by immunohistochemistry techniques. Only H\&E-stained slides were examined. Although monitoring of various biomarkers would have improved the detailed description of the tumors, H\&E staining was considered to be sufficient to allow accurate assessment of tumor necrosis, the most clinically relevant parameter in the context of TACE [35].

In conclusion cTACE performed by local infusion of a water-inoil emulsion of a low dose of oxaliplatin in Lipiodol was associated with lower systemic exposure, higher tumor/healthy liver parenchyma Pt ratios and more marked tumor necrosis than after intravenous infusion of a higher dose of this cytotoxic molecule in VX2 tumor-bearing rabbits. These results may warrant clinical studies in patients with unresectable HCC lesions.

\section{Conflicts of Interest and Financial Disclosures}

All authors are employees of Guerbet. The study was funded by Guerbet (Villepinte, France).

\section{Acknowledgment}

The authors thank Sanofi for providing kindly the Eloxatin ${ }^{\circledR}$. The authors thank Fannie Baudimont (DVM, Atlantic Bone Screen, Saint Herblain, France) and E. Renard (1), S. Rizzitelli (1), R. Santus ${ }^{(1)}$, M. Soares ${ }^{(1)}$, X. Violas (1) and C. Wallon ${ }^{(1)}$ at Guerbet, for their technical assistance.

\section{References}

1. Le Grazie M, Biagini MR, Tarocchi M, Polvani S, Galli A (2017) Chemotherapy for hepatocellular carcinoma: The present and the future. World J Hepatol 9(21): 907-920.

2. Qin S, Bai Y, Lim HY, Thongprasert S, Cha Y, et al. (2013) Randomized, multicenter, open-label study of oxaliplatin plus fluorouracil/leucovorin versus doxorubicin as palliative chemotherapy in patients with advanced hepatocellular carcinoma from Asia. J Clin Oncol 31(28): 3501-3508.

3. Qin S, Cheng Y, Liang J, Shen L, Bai Y, et al. (2014) Efficacy and safety of the FOLFOX4 regimen versus doxorubicin in Chinese patients with advanced hepatocellular carcinoma: a subgroup analysis of the EACH study. Oncologist 19(11): 1169-1178.

4. Zaanan A, Williet N, Hebbar M, Dabakuyo TS, Laetitia Fartoux L, et al. (2013) Gemcitabine plus oxaliplatin in advanced hepatocellular carcinoma: a large multicenter AGEO study. J Hepatol 58(1): 81-88.

5. Idée JM, Guiu B (2013) Use of Lipiodol as a drug-delivery system for transcatheter arterial chemoembolization of hepatocellular carcinoma: a review. Crit Rev Oncol Hematol 88(3): 530-549.

6. Konno T, Maeda H, Iwai K, S Tashiro, S Maki, et al. (1983) Effect of arterial administration of high-molecular-weight anticancer agent SMANCS with lipid lymphographic agent on hepatoma: a preliminary report. Eur J Cancer Clin Oncol 19(8): 1053-1065.

7. (2018) European Association for the Study of the Liver. EASL clinical practice guidelines: management of hepatocellular carcinoma. J Hepatol 69(1): 182-236.

8. Mazzaferro V, Citterio D, Bhoori S, Bongini M, Miceli R, et al. (2020) Liver transplantation in hepatocellular carcinoma after tumour downstaging (XXL): a randomised, controlled, phase $2 \mathrm{~b} / 3$ trial. Lancet Oncol 21(7): 947-956.

9. Marelli L, Stigliano R, Triantos C, Marco Senzolo, Evangelos Cholongitas, et al. (2007) Transarterial therapy for hepatocellular carcinoma: which technique is more effective? A systematic review of cohort and randomized studies. Cardiovasc Intervent Radiol 30 (1): 6-25.

10. Yamada R, Bassaco B, Bracewell S, Gillen K, Kocher M, et al. (2019) Longterm follow-up after conventional transarterial chemoembolization (CTACE) with mitomycin for hepatocellular carcinoma (HCC). J Gastrointest Oncol10(2): 348-353.

11. Boulin M, Guiu S, Chauffert B, Aho S, Cercueil JP, et al. (2011) Screening of anticancer drugs for chemoembolization of hepatocellular carcinoma. Anticancer Drugs 22(8): 741-748.

12. Pascale F, Bedouet L, Baylatry M, Namur J, Laurent A, et al. (2015) Comparative chemosensitivity of VX2 and HCC cell lines to drugs used in TACE. Anticancer Res 35(12): 6497-504.

13. Boulin M, Guiu B (2016) Which is the best chemotherapeutic agent for transarterial chemoembolization of hepatocellular carcinoma? Cardiovasc Intervent Radiol 39(6): 953-954.

14. Martínez-Balibrea E, Martínez-Cardús A, Ginés A, Vicenç Ruiz de Porras , Catia Moutinho, et al. (2015) Tumor-related molecular mechanisms of oxaliplatin resistance. Mol Cancer Ther 14(8): 1767-1776.

15. Dilruba S, Kalayda GV (2016) Platinum-based drugs: past, present and future. Cancer Chemother Pharmacol; 77(6): 1103-1124. 
16. Tashiro T, Kawada Y, Sakurai Y, Kidani Y (1989) Antitumor activity of a new platinum complex, oxalato (trans-1-1,2-diaminocyclohexane) platinum (II): new experimental data. Biomed Pharmacother 43(4): 251-260.

17. Montagnani F, Turrisi G, Marinozzi C, Camillo Aliberti, Giammaria Fiorentini (2011) Effectiveness and safety of oxaliplatin compared to cisplatin for advanced, unresectable gastric cancer: a systematic review and meta-analysis. Gastric Cancer 14(1): 50-55.

18. Deschamps F, Moine L, Isoardo T, L Tselikas, A Paci, et al. (2017) Parameters for stable water-in-oil lipiodol emulsion for liver transarterial chemo-embolization. Cardiovasc Intervent Radiol 40(12): 1927 1932.

19. André T, Boni C, Mounedji-Boudiaf L, Matilde Navarro, Josep Tabernero, et al. (2004) Oxaliplatin, fluorouracil, and leucovorin as adjuvant treatment for colon cancer. N Engl J Med 350(23): 2343-2351.

20. Boige V, Malka D, Elias D, Marine Castaing, Thierry De Baere, et al. (2008) Hepatic arterial infusion of oxaliplatin and intravenous LV5FU2 in unresectable liver metastases from colorectal cancer after systemic chemotherapy failure. Ann Surg Oncol 15(1): 219-226.

21. Li JH, Xie XY, Zhang L, Fan Le, Ning-Ling Ge, et al. (2015) Oxaliplatin and 5-fluorouracil hepatic infusion with lipiodolized chemoembolization in large hepatocellular carcinoma. World J Gastroenterol 21(13): 39703977.

22. Eloxatin Summary of Product Characteristics. US Food and Drugs Administration

23. Graham MA, Lockwood GF, Greenslade D, Silvano Brienza, Martine Bayssas, et al. (2000) Clinical pharmacokinetics of oxaliplatin: a critical review. Clin Cancer Res 6(4): 1205-1218.

24. Pendyala L, Creaven PJ (1993) In vitro cytotoxicity, protein binding, red blood cell partitioning, and biotransformation of oxaliplatin. Cancer Res 53(24): 5970-5976.

25. Urien S, Lokiec F (2004) Population pharmacokinetics of total and unbound plasma cisplatin in adult patients. Br J Clin Pharmacol 57(6): 756-763.

ISSN: 2574-1241

DOI: 10.26717/BJSTR.2021.37.006065

A Dencausse. Biomed J Sci \& Tech Res

CC (P) This work is licensed under Creative Commons Attribution 4.0 License

Submission Link: https://biomedres.us/submit-manuscript.php
26. Raza A, Sood GK (2014) Hepatocellular carcinoma review: Current treatment, and evidence-based medicine. World J Gastroenterol 20(15): 4115-4127.

27. Kizu R, Higashi S, Kidani Y, Miyazaki M (1993) Pharmacokinetics of (1R,2R-diaminocyclohexane) oxalatoplatinum (II) in comparison with cisplatin following a single intravenous injection in rabbits. Cancer Chemother Pharmacol 31(6): 475-480.

28. Dzodic R, Gomez-Abuin G, Rougier P, Marc Bonnay, Patrice Ardouin, et al (2004) Pharmacokinetic advantage of intra-arterial hepatic oxaliplatin administration: comparative results with cisplatin using a rabbit VX2 tumor model. Anticancer Drugs 15(6): 647-650.

29. De Baere T, Zhang X, Aubert B, C Lagrange, J Ropers, et al. (1996) Quantification of tumor uptake of iodized oils and emulsions of iodized oils: experimental study. Radiology 201(3): 731-735.

30. Llovet JM, Di Bisceglie AM, Bruix J, Barnett S Kramer, Riccardo Lencioni, et al. (2008) Panel of Experts in HCC-Design Clinical Trials. Design and endpoints of clinical trials in hepatocellular carcinoma. J Natl Cancer Inst 100(10): 698-711.

31. Lencioni R, Llovet JM (2010) Modified RECIST (mRECIST) assessment for hepatocellular carcinoma. Semin Liver Dis 30(1): 52-60.

32. Parvinian A, Casadaban LC, Gaba RC (2014) Development, growth, propagation, and angiographic utilization of the rabbit VX2 model of liver cancer: a pictorial primer and "how to" guide. Diagn Interv Radiol $20(4): 335-340$

33. Miyayama S, Matsui O, Yamashiro M, Yasuji Ryu, Keiko Kaito, et al. (2007) Ultraselective transcatheter arterial chemoembolization with a 2-f tip microcatheter for small hepatocellular carcinomas: relationship between local tumor recurrence and visualization of the portal vein with iodized oil. J Vasc Interv Radiol 18(3): 365-376.

34. Amptoulach S, Tsavaris N (2011) Neurotoxicity caused by the treatment with platinum analogues. Chemother Res Pract 2011: 843019.

35. Haywood N, Gennaro K, Obert J, Sauer PF, Redden DT, et al. (2016) Does the degree of hepatocellular carcinoma tumor necrosis following Transarterial chemoembolization impact patient survival? J Oncol 2016: 4692139.

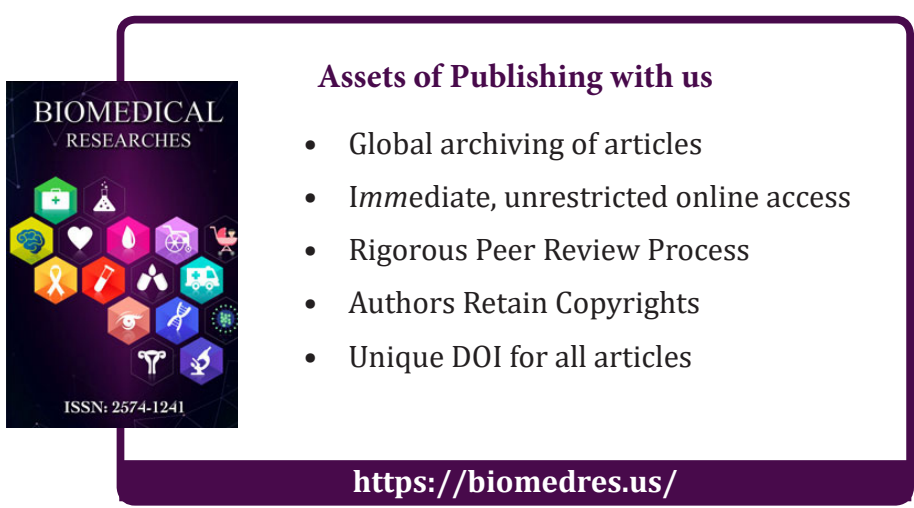

